\title{
VANGUARDAS E ESGOTAMENTO: AS TENSÕES DO MODERNO EM DOIS ARTISTAS
}

\author{
Maria Salete Borba ${ }^{*}$ \\ Universidade Federal de Santa Catarina \\ Rita Lenira de Freitas Bittencourt ${ }^{* *}$ \\ Universidade Federal do Rio Grande do Sul
}

Resumo: Este artigo propõe realizar uma leitura de dois artistas considerados modernos: o uruguaio Joaquín Torres-García e o português Amadeo de Souza-Cardoso. O ponto de partida desta reflexão é o verbete "Informe" de Georges Bataille, publicado no ano de 1929 no Dicionário crítico da revista Documents (1929-1931). Trazemos para a discussão a leitura realizada por Rosalind Krauss e Yve-Alain Bois, por ocasião da exposição L'informe. Mode d'emploi, em que o verbete batailleano é transformado em operação de caráter performativo. Partindo desses teóricos, pretende-se investigar os possíveis desdobramentos de alguns conceitos caros à modernidade, que circulam em torno do esgotamento das vanguardas e se elaboram em processo simultâneo aos próprios movimentos. Além dos trabalhos de Krauss e Bois, alguns textos críticos a respeito de outras obras de Bataille e também sobre a teoria da modernidade servem de referência, ao longo desse ensaio, para contrapor e apresentar as singularidades de duas produções artísticas.

Palavras-chave: Modernismo. Esgotamento. Joaquín Torres-García. Amadeo de SouzaCardoso. Vanguardas.

\section{Modos de ler}

Georges Bataille no ano de 1929 apresenta no Dicionário crítico da revista dedicada às artes e ideias Documents (1929-1931), breves linhas que revolucionaram o modo de pensar a literatura e as demais artes, antecipando algumas temáticas fundamentais para a teoria e a crítica modernas. Trata-se do verbete "Informe":

INFORME

(Documents, 7 - dezembro de 1929)

Um dicionário começaria a partir do momento em que ele não desse mais o sentido das palavras, mas sim suas obrigações. Assim, informe não é somente um adjetivo

Esta obra está licenciada sob uma Licença Creative Commons.

Maria Salete Borba é pós-doutora pela Universidade Federal de Santa Catarina. Contato: nena.borba@gmail.com

** Rita Lenira de Freitas Bittencourt é professora na Universidade Federal do Rio Grande do Sul e pósdoutoranda da CAPES na Universidade de Lisboa - CECFLUL. Contato: rita.lenira@ufrgs.br 
com certo sentido, mas um termo que serve para desorganizar, exigindo, geralmente, que cada coisa tenha sua própria forma. Isto que ele nomeia não aponta um caminho fixo e pode ser facilmente despedaçado, do mesmo modo que uma aranha ou um verme. De fato, para o contentamento dos acadêmicos, seria necessário que o universo tomasse forma. Toda a filosofia tem apenas um objetivo: trata-se de dar uma roupagem ao que já existe, uma roupagem matemática. Por outro lado, afirmar que o universo não se assemelha a nada e que ele não é nada além de informe retoma a afirmação de que o universo é algo como uma aranha ou um escarro. (BATAILLE, 2009, p. 6)

Pautada nos estudos de Georges Bataille, em especial no verbete Informe, Rosalind Krauss, em parceria com Yve-Alain Bois, organizou em 1996, no Centre Georges Pompidou, uma exposição que acolheu vários artistas e recebeu o título L'informe. Mode d'emploi. Nesta parceria, Bois e Krauss relêem o verbete batailleano como uma operação de caráter performativo, que se desdobra em quantidade de nomes e variedades técnicas.

Partindo dos textos desses teóricos, pretende-se trazer à tona e discutir os possíveis desdobramentos de alguns conceitos caros à modernidade, que circulam em torno do esgotamento das vanguardas e se elaboraram em processo simultâneo aos próprios movimentos. Além dos trabalhos de Krauss e Bois, alguns textos críticos a respeito de outras obras de Bataille e também sobre a teoria da modernidade servem de referência, ao longo desse ensaio, para contrapor e apresentar as singularidades de duas produções artísticas, retroagindo aos primeiros anos do modernismo. Além disso, optou-se por um formato híbrido, explorando o uso de verbetes, em deliberado jogo com a forma catálogo da exposição mencionada, na busca de experimentar teoricamente uma disposição espacial alternativa.

Essas reflexões acompanham os trajetos e algumas obras de dois artistas: o uruguaio Joaquín Torres-García e o português Amadeo de Souza-Cardoso, considerando que suas marcas em direção ao informe são estabelecidas nos trânsitos entre materiais distintos e nas conexões e desconexões com os postulados e projetos das vanguardas.

\section{Modos de ver}

Ver é ler por intervalos, colocando performaticamente em cena encontros improváveis em tempos e espaços diferentes. Além de provocar efeitos anacrônicos, o informe circula em zonas transtemporais e transnacionais. Em proposta de diálogo e jogo, ao invés de tópicos ou subtítulos, nesse caso, o ensaio monta-se em verbetes:

\section{Torres-García | 1874-1949}

No texto da exposição Joaquín Torres-García: constructing Abstraction with Wood (2009), organizada por The Menil Collection e pelo Museum of Fine Arts, é lembrada a 
formação de Torres-García em Barcelona, em especial nas oficinas do arquiteto/artista Antoni Gaudí (1952-1926) no início do século XX.

Torres-García found his artistic voice while studying at Barcelona's Academia Baixas and Cercle Artístic de Sant Lluc from 1893-1898. He delved into Catalan Modernism and collaborated with Antoni Gaudí in the workshops of the Sagrada Familia (1904-1905). ${ }^{1}$

Sabe-se, também, que Joaquín Torres-García nasceu no Uruguai e que durante sua vida morou em várias cidades, além de Barcelona: Nova Iorque, Itália, Paris, Madri. Após 43 anos retornou ao país em que nasceu. Este ir e vir nos faz ler em seus trabalhos mais que o artista nômade/viajante, ou seja, nos faz ler em sua trajetória, assim como, na mescla de imagem e escrita de seus trabalhos, os contatos entre a vanguarda europeia e latino-americana.

Lembramos também que a trajetória artística de Torres-García, o seu trânsito pela Europa e Américas, os contatos que manteve com a vanguarda construtiva/abstrata - Theo van Doesburg, Piet Mondrian, Jean Arp, Georges Vantongerloo, Kurt Schwitters, nesse caso, inclui-se também o escritor/crítico Michel Seuphor -, nos revela que ao invés de rompimentos com o passado, há em sua poética, em especial na série de brinquedos realizados na década de 1920, a convivência de elementos, de interesses e culturas diferentes.

Tais características e referências, além de revelarem o anacronismo existente nos trabalhos de Torres-García, apresentam o aprendizado do artista, interessado, por um lado, na arte de cunho tradicional/clássico; por outro lado, na arte abstrato/construtivista pautada numa perspectiva em que a forma é um meio para se atingir o universal.

Nesse sentido, há nos brinquedos articulados de Torres-García, traços do racionalismo advindos das investigações concreto/abstratas, mas, ao mesmo tempo, podemos constatar o caráter orgânico desses trabalhos que "nascem" híbridos como a arquitetura de seu mestre Gaudí.

\section{Amadeo de Souza-Cardoso | 1887-1918}

A exposição Sob o signo de Amadeo: um século de arte, de julho de 2013 a janeiro de 2014 no Centro de Arte Moderna da Fundação Calouste Gulbenkian, em Lisboa, pretende, segundo o texto do catálogo de apresentação, mostrar "pela primeira vez a quase totalidade do espólio de Amadeo de Souza-Cardoso (Manhufe, 1887 - Espinho, 1918), o pintor português que foi precursor do modernismo e uma das âncoras iniciais da coleção do CAM." (CARLOS, 2013, p.2).

\footnotetext{
${ }^{1}$ Disponível em: http://ebookbrowsee.net/joaquintorres-garciaatthemenilcollection-pdf-d686669788. Acesso em: 4 abr 2014.
} 
Assinam a curadoria, além de Isabel Carlos, Ana Vasconcelos e Melo, Leonor Nazaré, Patrícia Rosas e Rita Fabiana. A exposição das obras de Amadeo, conjugada a uma revisita ao acervo, foi uma atividade comemorativa aos 30 anos do CAM. Assim, em sua concepção, a proposta convida a "uma viagem por todo o século XX", pois "para além de mostrar o acervo quis-se também sublinhar o lugar, hoje, do museu como laboratório, espaço de criação e risco" e elege "a performance como uma das linhas da programação" (CARLOS, 2013, p. 2).

Nas escolhas explicitadas e também no texto citado, Isabel Carlos relaciona Amadeo Souza-Cardoso não apenas à teoria e à linguagem da performance e aos ready-made de Marcel Duchamp, como também o insere no bojo do que denomina "história das vanguardas" e "rutura modernista", que se dá na conjunção de três movimentos: o construtivismo, o futurismo e o dadaísmo. Além disso, traz à cena plástica as relações de Amadeo com a literatura de Fernando Pessoa, do heterônimo Álvaro de Campos, e também de Mário de SáCarneiro. Com o artista múltiplo e escritor Almada Negreiros o pintor efetivamente realizou trocas criativas ${ }^{2}$.

É preciso sublinhar, no entanto, que é o diálogo de Amadeo e sua simultânea independência das vanguardas que o insere em um contexto de afirmação e interrogação, em um paradoxo fundador que tem no informe, entendido como fuga permanente da forma, uma de suas materializações.

\section{Art toys}

A maioria das exposições e fortuna crítica dedicadas ao artista Joaquín Torres-García tiveram como foco principal suas pinturas, ou melhor, a mescla entre pintura, desenho e escritura. No entanto, há uma parte da produção do artista uruguaio em que se destaca a produção de brinquedos. Os brinquedos foram realizados na década de 1920, e ficaram conhecidos como Art toys.

Cecilia de Torres no texto The essence of the Art (TORRES, 2009, p.1) destaca duas exposições nas quais, ao invés de pinturas, foi mostrado ao público uma parte singular da poética do artista uruguaio que são seus brinquedos e construções pictóricas sobre madeira: Aladdin Toys, 1997, que ocorreu na Espanha, e Joaquín Torres-García: constructing

\footnotetext{
${ }^{2}$ Ver, por exemplo, NEGREIROS, José de Almada. K4 O Quadrado azul. Lisboa, 1917. Edição Gráfica a cargo de Amadeo de Souza-Cardoso. (Catálogo 1, 2007)
} 
Abstraction with Wood, 2009, organizada por The Menil Collection e pelo Museum of Fine $\mathrm{Arts}^{3}$, em Houston, que apresentou uma série de pinturas sobre madeira.

De acordo com Adolfo M. Maslach (1992) é o caráter heterogêneo que advém das construções construtivistas de Torres-García que estão presentes nesta série que é: arte e brinquedo, relevo e pintura, primitivo/arcaico e concreto/abstrato.

Podemos ler nestas imagens dos anos 1920, realizadas no período em que o artista estava mudando-se para Nova Iorque que, além da preocupação com o interior e com a compreensão formal, outras preocupações atravessam o processo artístico do artista uruguaio que resolveu comercializar seus brinquedos e criou a fábrica que se chamou Aladdin Company. "In 1917 he abandoned the Classically inspired style for contemporary and dynamic paintings inspired by modern urban life and in 1920, he moved to New York the most modern of all cities." (TORRES, 2009, p. 12).

O movimento que é oferecido pela metrópole é assimilado, e além de simular vem agregar força ao corpo/forma que vinham sendo estudados. Assim, os brinquedos, estas formas lúdicas, ultrapassam os fins didáticos, ou seja, este corpus feito de fragmentos de madeira recortados expõem ao mesmo tempo o lado enigmático da escrita e as formas arcaicas que, muitas vezes, ensaiam danças a partir de suas articulações, e n-possibilidades de montagem que revelam as preocupações do artista/pai em relação ao público/filhos. Ou melhor, revelam a vontade de estar com que está na palavra "contemporâneo", de compartilhar o momento, o instante, o inapreensível. Este desejo que está no gesto de brincar/fazer, de interagir, de estar junto, é, também, por assim dizer, inapreensível, tal como Georges Bataille caracteriza a arte moderna.

\section{Caricaturas, desenhos, colagens e pinturas "de amador"}

Entre o experimental e o jornalístico, as primeiras obras vindas a público de Amadeo Souza-Cardoso serão caricaturas, publicadas em jornais portugueses e parisienses. Suas práticas pictóricas surgem tardiamente, pois tanto ao deslocar-se a Lisboa quanto, mais adiante, a Paris, o que o artista pretendia era estudar arquitetura, embora desenhasse desde criança e seus trabalhos remontem à adolescência. Considerando-se, ainda, que seu tempo de vida foi bastante curto, pois faleceu com apenas 31 anos, é de espantar que em poucos anos possa ter produzindo uma obra tão variada e múltipla, passando por técnicas distintas e sem nunca se confinar aos parâmetros ou modismos de quaisquer movimentos.

\footnotetext{
${ }^{3}$ Disponível em: http://ebookbrowsee.net/joaquintorres-garciaatthemenilcollection-pdf-d686666788 Acesso em: 04 abr 2014.
} 
No primeiro Catálogo Raisonée, de 2007, constam algumas informações a respeito de certa condição alternativa do artista. Se as caricaturas são criadas por brincadeira, em cadernetas escolares e cartões postais, mas chegam, algumas vezes, aos jornais, são trabalhos que, aos poucos, abrem caminho para produções de maior qualidade. As primeiras críticas, em relação a seus $X X$ Desenhos, exibidos em Paris, identificam elementos que remetem Amadeo a uma origem tropical, embora, em termos técnicos, sejam trabalhos em preto e branco ${ }^{4}$, feitos a nanquim, em delicada caligrafia, onde predominam fauna e flora, mas surgem também motivos orientais, bruxas e até uma leitura do Quixote.

Mais adiante, se assinalará algo semelhante em relação às pinturas, de "cores africanas", tomando-as como marcas de exotismo e distanciamento da tradição europeia. Em cartas, o próprio Amadeo atribui seus impulsos intensos e suas variações de humor ao "sangue árabe" que herdou de seus antepassados. Por outro lado, Mário de Sá-Carneiro, morador de Paris na mesma época, não gosta do pintor, nem de seus trabalhos, e o adjetiva de esnobe, ligando-o aos futuristas.

José-Augusto França (1960) considera os trabalhos de Amadeo, entre 1908 e 1911, pinturas "de amador", nos quais ele explora castelos e figuras heráldicas, caracterizando um "bizantinismo estilístico" que lembra Klimt. Nos anos seguintes, o pintor estabelecerá relações formais com o cubismo, mas com diferenciações que o conduzem ao abstracionismo. De certo modo, ainda segundo França, ao pensar os volumes, o artista antecipa a teoria de $O$ Purismo, de Ozenfant, de 1915, e também passa pelo expressionismo, nas ênfases e usos de pinceladas e nas pinturas de cabeças, por exemplo, formas que já vinham sendo exploradas desde os desenhos e caricaturas.

No artigo "Critérios e metodologias", que acompanha o Catálogo Raisonée de 2008, Catarina Alfaro fornece a lista das exposições do artista realizadas em quatro anos:

\author{
1911: XXVII Salon des Independants \\ 1912: XXVIII Salon des Independants \\ 1912: X Salon d'Automne \\ 1913: Armory Show \\ 1913: Erster Deutscher Herbstsalon \\ 1914: London Salon of the Allied Artist'Association \\ 1914: Exhibition of Paiting and Sculpture in "The Modern Spirit", Milwaukee Art \\ Society (ALFARO, 2008, p.108).
}

\footnotetext{
${ }^{4}$ Carlos Camposa, no texto de introdução à edição comemorativa ao centenário de nascimento do pintor, que publica novamente o álbum dos XX Desenhos (cuja 1 ${ }^{a}$. Edição é Paris, 1912), levanta algumas características: o aspecto lírico, o aspecto onírico, as reminiscências "quase bizantinas", aspectos heráldicos e figurativismo (que inclui simbolismo dos contornos e altivez das personagens) e, por fim, a elegância. E comenta: "Fala-se do Cubismo no prefácio desse livro. (...) É óbvio que certas ideias programáticas e muito da estética cubista estão nesses desenhos. Mas, a meu ver, é um cubismo atenuado, amável, quase cerimonioso, que aqui se vislumbra..." (CAMPOSA, 1987, p. 12).
} 
Algumas fotografias, ainda segundo Alfaro, fornecem pistas a respeito das obras que participaram dessas várias exposições, quando não há maior documentação a respeito. Além disso, as fotos desenham o movimentado e brilhante contexto intelectual e artístico dos primeiros anos do século XX:

Destaca-se a fotografia do X Salon d'Automne, publicada originalmente no periódico no periódico L'Illustration onde figuram as obras de Amadeo: Le moulin e Après le bain, ladeando Danse à la source, de Picabia. À frente são expostas quatro esculturas de Modigliani. À esquerda surge Fugue em deux tons, de Kupka. Do lado direito de Après le bain aparece Metzinger, aqui representado com duas obras ( $L a$ danseuse e Paysage), seguido de Le Fauconnier (Les montagnards ataques par les ours) (ALFARO, 2008, p. 109.)

A cópia do catálogo (ALFARO, 2008) da Exposição de 1916, no Porto, oferece uma visão panorâmica da mobilidade de Amadeo. Dois anos antes de morrer, o artista traz a público 80 pinturas a óleo, 4 pinturas a cera, 19 aquarelas e 10 desenhos.

Nesse período, tendo retornado a Portugal, atinge o domínio das técnicas pictóricas ao mesmo tempo em que estabelece uma relação parcial com os futuristas lisboetas, como Almada Negreiros e Santa-Rita Pintor, companheiros da Revista Orpheu ${ }^{5}$. Torna-se um dos divulgadores da arte moderna no país e nos últimos anos se aproxima do dadaísmo, em formas revisitadas de nus e em colagens que explodem as categorias da pintura tradicional.

Por conta dessa condição caleidoscópica, França (1960) comenta que só na década de 30 do século XX se viria a descobrir e a explorar, teórica e criticamente, em Portugal, as qualidades da "obra incerta e irregular" de Souza-Cardoso.

\section{Arte moderna}

Hal Foster em Prosthetic gods (2004) ao ler a arte moderna a partir da psicanálise chega à conclusão de que artistas como Paul Gauguin, Pablo Picasso, F. T. Marinetti, Wyndham Lewis, Adolf Loos, Max Ernst, Paul Klee e Jean Dubuffet em seus trabalhos revelam uma busca pela origem. Ou melhor, grande parte dos artistas modernos, segundo Foster apresentam, cada um a sua maneira, "ficções de origem".

In the first instance this book is concerned with such imaginings in work and writing by key modernists like Paul Gauguin and Pablo Picasso, F. T. Marinetti and Wyndham Lewis, Adolf Loos and Max Ernst, Paul Klee and Jean Dubuffet. These

\footnotetext{
${ }^{5}$ Orpheu foi uma Revista Trimestral de Literatura, editada em Lisboa, que teve apenas dois números publicados, correspondentes aos primeiros dois trimestres de 1915, tendo o terceiro número cancelado devido a dificuldades de financiamento. Apesar disso, a revista inspirou movimentos literários subsequentes de renovação da literatura portuguesa. Associaram-se ao projeto importantes nomes das letras e das artes, como Fernando Pessoa e Mário de Sá-Carneiro, além de Almada Negreiros e Santa-Rita Pintor e Amadeo Souza-Cardoso, que tornaram-se conhecidos como "a geração d'Orpheu".
} 
figures are diverse, but they are all fascinated by fictions of origins that are at once aesthetic and subjective. [...] (FOSTER, 2004, p. X)

A busca por "Ficções de origem", de certo modo, também pode ser lida em TorresGarcía. Na série de brinquedos da década de 1920, encontramos a infância/origem revisitada, que é recuperada no texto, já citado, de Cecilia de Torres e que nos lembra que o artista uruguaio era filho de um comerciante de uma grande loja, a qual, entre diversos ambientes, comportava uma marcenaria onde o menino Joaquín Torres-García pode realizar os primeiros experimentos com madeira.

Torres-García's attraction to wood as a material started in his childhood. His Spanish father had immigrated to Montevideo driven like so many of his countrymen, to make a fortune in America. He opened a general store in the outskirts of Montevideo, where the gauchos from the countryside came to buy supplies and sell their products. The store had a large warehouse, stables, a bar, and a carpentry shop, where Torres-García first experimented with constructing in wood. $\mathrm{He}$ also enjoyed opening and assembling the boxes of imported goods, such as sewing machines, furniture, and tractors. In spite of Uruguay's obligatory school education, the young lad regularly ran away preferring to study at home by himself. (TORRES, 2009, p. 12)

Por outro lado, nos é revelado nesses trabalhos mistos, desenhos que se desdobram em escrita, escrita que recupera formas, formas que são esculturas planas, chapadas, modulares. Assim, o artista dá um passo além da reprodução de um modelo já estabelecido, e vem à tona, nesses brinquedos, o interesse de Joaquín Torres-García em compreender, em fazer parte das discussões que envolviam não somente arte, mas, a arte com a vida em seus desdobramentos poéticos/políticos.

É essa escritura que se apropria, que se desdobra em desenho, objeto, brinquedo que se dá "no" e "pelo" contato com imagens advindas de outros meios, e, também, de outros tempos, que fala de uma época em que as questões relacionadas ao corpo e ao movimento, que está presente na poética de Torres-García. Assim, pode-se dizer que a modernidade é palco de investigações artísticas do artista uruguaio, e é nela que estão inseridos a série de brinquedos articulados, recortados, montados, que ficou conhecida como Aladdin toys.

A série de brinquedos de Torres-García é datada de 1910 a 1925, época em que o artista passa a observar que seus filhos ao brincar quebram os brinquedos para ver o que há no interior. Este momento de contemplação do ato de brincar é de grande valor investigativo para o artista. A partir de suas observações não somente o ato de brincar é resgatado, mas a necessidade de criar objetos/brinquedos que ultrapassem a simples experiência lúdico/pedagógica, fazendo com que a manipulação e a montagem façam parte intrínseca do ato de brincar/criar. Sendo assim, Torres-García ao fabricar brinquedos em madeira para 
serem manipulados e/ou montados de diversas maneiras nos permite ler nestes trabalhos mais que a simples construção de objetos lúdicos. Nestes brinquedos o artista une o universal, o formal, com o particular, que é, por um lado, um momento de introspecção e de certo retorno, e, por outro lado, uma sorte de fuga do caráter já estabelecido. Eis a busca pela origem que está no ato de observar o momento em que o brinquedo é quebrado para se ver o que há dentro, mas, também, no próprio processo criativo, como pode ser visualizado na sua trajetória, e que atravessa a escritura do artista. Ou seja, o resultado não é o abandono das formas clássicas, mas a vontade de integrar, de equilibrar num único objeto forma e força.

Conforme lemos no texto de Cecília de Torres, a erudição do artista uruguaio mescla além do interesse pelas diversas vertentes artísticas, o interesse pelo esoterismo, pela filosofia, e pelas diversas culturas que vêm à tona já na escolha do nome de seus filhos. Nesse caso, Torres-García recorre às culturas grega e romana.

\begin{abstract}
They had four children they gave Greek and Roman names: Olimpia, Augusto, Iphigenia and Horacio. Torres-García observed them at play, and seeing that they broke their toys to learn how they functioned, he realized that they didn't answer the child's need to learn playing. He designed toys in parts that could be interchanged and became so involved with their creative and didactic possibilities that he teamed with a carpenter to produce toys which he called "art toys," and created the Alladin Company. (TORRES, 2009, p. 12)
\end{abstract}

Além da preocupação com as formas, não nos esqueçamos do interesse de TorresGarcía pelo esoterismo ${ }^{6}$ vem a agregar valor à sua poética, em que buscava a integração entre arte e vida. E é com esta poética híbrida que, como já afirmamos anteriormente, as investigações artísticas de Torres-García em busca por uma origem se consolidam. Ou melhor, concordando com Hal Foster, Torres-García, assim como outros artistas modernos, ao voltar-se para as investigações em torno do corpo/corpus/brinquedo que se desdobra, que se fragmenta para em seguida ser remontado, apresenta-nos mais que um objeto acabado, uma poética que é composta por "ficções de origens". Tais investigações nos fazem lembrar das palavras do filósofo italiano Giorgio Agamben, em especial aquelas do texto $O$ que é $o$

\footnotetext{
${ }^{6}$ Adolfo M. Maslach no texto "Del esoterismo en el arte de Joaquín Torres-García" comenta o interesse de Torres-García pela compressão interior de si mesmo que podem ser lido em textos nos quais o artistas reflete sobre esta questão: El descubrimiento de sí mismo (1917); Historia de mi vida. Maslach afirma: "Esoterismo" significa no solamente una categoria o forma especial de conocimiento, sino también uma actitud particularmente acerca del conocimiento, por cuanto supone una distinción entre el conocimiento común, superficial, y um conocimiento "interior", auténtico, centrado en la naturaleza de lo "real". La importância que este principio tuvo para Torres-García puede apreciarse en un ensayo inédito, titulado "Del esoterismo en el arte", de fecha 23 de octubre de 1932, época en que Torres-García se hallaba consagrado a sintetizar sus ideas teóricas alimentadas por muchas fuentes en el compendio estético que denomino universalismo construtivo [...]. Este texto poço conocido brinda una noción de los princípios y objetivos claves de la estética, desde épocas antiguas, que há dominado todo el aprendizaje humano, inclusive en la esfera del arte. (MASLACH In FLETCHER, 1992, p. 149)
} 
contemporâneo? (2009) em que traz à tona o conceito de contemporâneo, e o apresenta revelando seu lado anacrônico que é vinculado, por um lado, ao arcaico, e, por outro lado, ao devir histórico:

[...] a contemporaneidade se escreve no presente assinalando-o antes de tudo como arcaico, e somente quem percebe no mais moderno e recente os índices e as assinaturas do arcaico pode dele ser contemporâneo. Arcaico significa: próximo da arké, isto é, da origem. Mas a origem não está situada apenas num passado cronológico: ela é contemporânea ao devir histórico e não cessa de operar neste, como o embrião continua a agir nos tecidos do organismo maduro e a criança na vida psíquica do adulto. A distância - e, ao mesmo tempo, a proximidade - que define a contemporaneidade tem o seu fundamento nessa proximidade com a origem, que em nenhum ponto pulsa com mais força do que no presente. (AGAMBEN, 2009, p. 69)

Caricatura das irmãs Suggia por Amadeo de Souza-Cardoso.

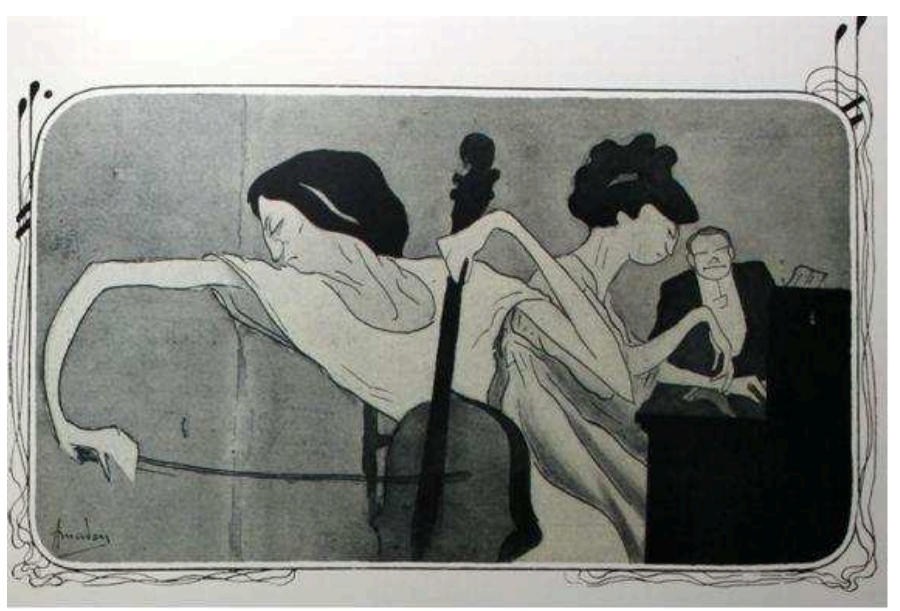

Fonte: [Paris], 1909. Revista semanal dos acontecimentos da vida portuguesa. No. 159 (8 Mar. 1909), p. 312.

Amadeo de Souza-Cardoso é amigo de Brancusi, que conhece através de Modigliani, e, algum tempo depois, se aproxima também de Boccioni. Monta vários ateliês na capital francesa, um deles em Montparnasse, na Rue Fleurus, 27, ao lado de Gertrude e Leo Stein. Participa de um complexo jogo de referências e suas preferências se dão em campo plural, tanto ao sabor de suas inclinações quanto em produções de base e articulação coletiva.

O pesquisador Michel Surya, prefaciador da edição em português de alguns textos de Bataille, aponta, ao comentar o artigo A mutilação sacrificial e a orelha cortada de Vicente Van Gogh, em relação ao teórico francês, certa condição de inacabamento e maneirismo de sua obra, que aqui se poderia estender ao pintor português. Diz Surya:

A maneira de Georges Bataille (talvez "maneira" seja melhor do que "método"), posta logo a funcionar neste primeiro artigo importante, será dentro em pouco a dos seus seguidores; um conhecimento apressadamente adquirido, graças a alguns textos de referência, a algumas conversas, e a um acrescento, pelo menos um acrescento de caráter mais intuitivo que dedutivo, mais perspicaz do que lógico, garantidamente pessoal (nascido de um jogo com a experiência feita em si próprio), a maior parte 
das vezes um acrescento singularmente desviado e, no entanto, esclarecedor. (Grifo do autor - SURYA, 1994, p. 15)

Pode-se pensar em "maneira" ou "desvio", ao invés de "método", também em relação a Amadeo, muito por conta de suas relações e trânsitos, mas também por certas obsessões pessoais, guiadas pela intuição, como a que o leva a produzir, em 1912, um manuscrito ilustrado do livro de Flaubert, La legende de St Julien l'Hospitalier ${ }^{7}$, que difere significativamente do que vinha propondo até então, aproximando-se da literatura infantil, do trabalho com gravuras, por um lado, e das práticas medievais de iluminuras e molduras textuais, por outro.

De certo modo, as marcas do anacronismo convocadas ao contexto moderno, reinventam-se em formas que recriam ou redesenham origens, inventando-as várias e ao sabor de forças múltiplas - montando-as como performances do eu, autoficções que acabam por ultrapassar o campo individual (auto) para tornarem-se ficções de um período, de um tempo e lugar especiais, de um campo de forças que alguns críticos vão denominar primeiro modernismo.

\section{Jogos}

Johan Huizinga em seu clássico livro Homo ludens (1938), ao definir o conceito de jogo recorre ao estudo linguístico para demonstrar a complexidade que toca tal conceito. Como pode ser conferido o estudioso holandês não se restringiu a uma definição única para a palavra, preferindo, portanto, desdobrá-la, incorporando, assim, outras designações que aparecem no processo de passagem/tradução de uma língua para outra. Portanto, o processo de tradução de um conceito que aparentemente pode ser considerado simples, passa a expor a sua complexidade como lemos nas palavras de Huizinga quando se refere ao conceito de jogo:

[...] nas línguas semíticas o conceito de jogo parece possuir um caráter um tanto ou quanto mais vago e fluido do que nas outras línguas que até aqui analisamos. Conforme veremos, o hebreu apresenta provas cabais da identidade entre o agonístico e o lúdico. Contrastando fortemente com a heterogeneidade e a instabilidade das designações da função lúdica em grego, o latim cobre todo o terreno do jogo com uma única palavra: ludus, de ludere, de onde deriva diretamente lusus. Convém salientar que jocus, jocari, no sentido especial de fazer humor, de dizer piadas, não significa exatamente jogo em latim clássico. Embora ludere possa ser usado para designar os saltos dos peixes, o esvoaçar dos pássaros e o borbulhar das águas, sua etimologia não parece residir na esfera do movimento rápido, e sim na da não-seriedade, e particularmente na da "ilusão" e da "simulação". Ludus

\footnotetext{
${ }^{7}$ Ver Amadeo de Souza-Cardoso (1887-19180). Gustave Flaubert - La Légende de Saint Julien L'Hospitalier [Paris]. 1912. Exemplar único caligrafado e ilustrado pelo artista. 143 Fólios (83 ilustrados) montados em carcelas. Papel de trapo (?) com a marca de água 1912 England em alguns fólios. Coleção CAM - Fundação Calouste Gulbekian, Lisboa. (Catálogo 2, 2008). Uma Edição fac-símile deste trabalho, em tiragem limitada, foi publicada pela Fundação.
} 
abrange os jogos infantis, a recreação, as competições, as representações litúrgicas e teatrais e os jogos de azar. Na expressão lares ludentes, significa "dançar". Parece estar no primeiro plano a idéia de "simular" ou de "tomar o aspecto de". (HUIZINGA, 2000, p. 26)

Cecilia de Torres apresenta a exposição de relevos/pintura sobre madeira, nota-se ainda um ponto de vista modernista que lê nessas imagens de Torres-García certa relutância em deixar o passado, em romper com o tempo, como lemos na seguinte passagem:

\begin{abstract}
Constructing Abstraction with Wood challenges the paintings relevance over the wood constructions. The exhibition demonstrates that in fact they represent a new direction in his research bringing the three dimensional realm into his painting. They are a very personal interpretation of the idiom of relief and pure abstract form. On one hand they relate by their rough look and in some cases an animistic aura to primitive art, but they also embody the geometric and constructivist idiom, that characterizes Torres-García's dilemma: his reluctance to let go of the art of the past for a total embrace of the present. (DE TORRES, 2009, p. 12)
\end{abstract}

A crítica se esquece de que é justamente a convivência do primitivo com o geométrico que tornou singular a obra de Torres-García, que o colocou lado a lado com grandes nomes da arte moderna, e que o manteve, ao mesmo tempo, distante devido à singularidade de sua obra.

\title{
Guerra
}

A primeira guerra mundial teve um efeito ao mesmo tempo produtivo e devastador em Amadeo Souza-Cardoso. Por conta dela, Amadeo e sua esposa, Lucie Pecetto, fixam residência em Portugal, na interiorana Manhufe, terra natal do pintor. No entanto, o artista não perde o contato com os vanguardistas, pois o casal Sónia e Roberto Delaunay, que havia conhecido em 1911, muda-se para o Porto, igualmente por conta da Guerra.

Com os Delaunay, Amadeo havia ampliado muito seu círculo de amigos em Paris. Passara a conviver com Marie Laurencin, Gleizes, Le Fauconnier, Chagall, Archipeko, Picabia, Severini e com os pintores do Blaue Reiter como Kandinsky, Klee, Marc, Macke. Conhece também Cendrars e obtém um encontro com Gaudí, na Catalunha, em 1914.

Nos anos que seguem, as mudanças contextuais são significativas:

O cenário da guerra, responsável pelo isolamento de Amadeo em Manhufe, alterou por completo a vida (artística) dos seus companheiros de Paris: Apollinaire foi gravemente ferido, Blaise Cendrars perdeu o braço direito em combate; Modigliani foi rejeitado pelo exército devido à sua debilidade física; Robert e Sónia Delaunay viajam para Madrid, acabando de se fixar em Vila do Conde (na Villa Simultanée) depois de uma breve passagem por Lisboa, onde conhecem um grupo de jovens artistas portugueses constituído por Almada Negreiros, Eduardo Viana e José Pacheco. (ALFARO, 2007, p. 219). 
Dentro das possibilidades que os tempos turbulentos permitiam, os Delaunay atraem um grupo de artistas que vai formar a Corporation Nouvelle, com o propósito de manter intercâmbios, divulgar trabalhos, organizar exposições e produzir em parceria: Amadeo, Almada, Pacheco, Viana, de Portugal, e Baranoff-Rosiné, pintor russo que vivia em Paris. Mais tarde, juntam-se a eles Apollinaire e Cendrars.

Em 1916, no entanto, as tentativas de exposições internacionais falham ${ }^{8}$, mas Amadeo, que vinha trabalhado febrilmente, realiza no Porto a Exposição de Pintura (Abstracionismo): Amadeo de Souza Cardoso, que causa grande repercussão e espanto. O público estranha os trabalhos, a crítica local reage com ironia, mas Walter Pach, marchand norte-americano que havia levado Amadeo ao Armory Show, comenta que esta foi "a primeira grande exposição de pintura moderna em Portugal” (ALFARO, 2007, p. 243). Alguns meses depois, a exposição repete-se em Lisboa, dessa vez com os ânimos menos agitados, sem a designação Abstracionismo no título e com alguns elogios em artigos jornalísticos. Nas entrevistas, o artista reforça sua postura de não pertencer à escola alguma.

O envolvimento com Almada Negreiros, em projetos tipográficos na revista Portugal Futurista, Número 1, e as experiências com óleo e colagens sobre tela serão desenvolvidas nos anos seguintes, 1917 e 1918. No entanto, apanhado em um surto de gripe espanhola, que dizimou 20 milhões de pessoas, Amadeo morre e deixa em aberto uma obra variada e pouco ortodoxa.

As fraturas da guerra e a fartura das pinturas se sobrepõem e dolorosamente se suplementam. Não por acaso, o subtítulo dos Calligrammes, de Guillaume Apolinaire, publicados em Paris, 1925, será Poèmes de la paix et de la guerre (1913-1916).

\section{Amor}

David Wills em Prosthesis (1995) traz à baila além de uma leitura que aproxima e mescla biografia com teoria, um olhar ímpar para a literatura lendo no cotidiano, nas memórias o ritmo, as pausas que transforma a vida em poesia. No entanto, não se esquece de que ao mesmo tempo a poesia, este ato artificial da linguagem, aponta as fraturas e as npossibilidades que advém da articulação da arte com a vida. Prosthesis é o primeiro volume de uma série de três livros: Prosthesis (Stanford, 1995); Dorsality (Minnesota, 2008);

\footnotetext{
8 “Em março de 1916, Robert Delaunay é convocado a se apresentar em Vigo para rever a sua situação militar e Sónia, que o acompanhou, é vítima de uma acusação de espionagem, ficando retida no Porto até 25 de abril. Após estes episódios, os Delaunay acabam por se instalar em Valença do Minho e em 1917 partem para Vigo, depois para Siges e, por fim, Madrid." (ALFARO, Nota 16. Idem, Ibidem, p.320). Evidentemente, esses contratempos contribuem para o fracasso das exposições planejadas.
} 
Inanimation (em processo). O primeiro livro é composto por nove fragmentos cujos títulos são nomes de cidades, e um deles de um continente. Todos os nomes estão acompanhados de números que revelam, marcam e nos inserem numa possível temporalidade: Hamilton, 1970; Mentone, 1888; África, 21st Century, Berchtesgaden, 1929; Paris, 1976; Rome, 1985; Cambridge, 1553; Menton, 1921; Geneva, 1978. Detemo-nos no primeiro fragmento, ou primeiro capítulo, chamado "Hamilton, 1970", que é uma sorte de homenagem ao pai.

Ao iniciarmos a leitura nos deparamos com uma descrição feita num fôlego só. Um longo parágrafo de 56 linhas escrito apenas com vírgulas para marcar o ritmo e as pausas. A primeira impressão é que estamos diante de uma performance em que não conhecemos nem os atores, nem o tema. Apenas descrições de movimentos, repetições, gestos que revelam dor. A dor, assim como a linguagem, é uma espécie de barreira, de fantasma. E assim a prótese nos é apresentada por um lado como algo artificial - a perna mecânica -, mas, por outro lado, o crítico também aponta a linguagem e, mesmo o corpo como desdobramentos da prótese. David Wills além de mesclar teoria com biografia/ autobiografia, expõe como ambas podem fazer parte do mesmo espaço vinculado à dor, ao corpo e, também, à linguagem. E assim, ao ritmo da poesia de Virgílio, outras boas surpresas surgem. Voltamos no tempo e ouvimos com o homem os sons, os galopes que o menino ouvia. Galopes de um cavalo vêm à tona, ora a partir da repetição de um único verso do poema Eneida, que acalmava e controlava os espasmos do pai, ora a partir dos galopes que advinham do prazer de brincar que possibilitava ao menino compartilhar outros momentos, além daqueles marcados pela dor fantasma.

A partir desta breve passagem podemos dizer que assim como Joaquín Torres-García deixou-se envolver pelos jogos, pelos gestos de seus filhos, David Wills revela-se um excelente observador/leitor e faz da contemplação do pai uma fonte para sua escritura. Ambos captaram no ato de observar o cotidiano a essência vital que podemos chamar amor. $\mathrm{O}$ ato de amar em Torres-García e David Wills se dá a partir de uma contemplação, ou melhor, de uma observação que ultrapassa o voyeurismo. É, por assim dizer, a capacidade de ler no efêmero, no ato banal, no cotidiano, maneiras de transformar a leitura em obra de arte.

No caso de Torres-García a observação dos gestos que o encantaram no ato de brincar de seus filhos resultou num processo criativo que nos revela uma poética que se desdobra em viagem, negócio - a fábrica de brinquedos Alladin Company -, e numa revista Cercle et carré - em vida.

Do mesmo modo, Wills transforma as memórias da infância, os gestos, a dor, a linguagem, a voz do pai declamando, repetindo o verso da Eneida de Virgílio em leitura, em 
literatura, em crítica, em negócio, em vida. O amor, em ambos os artistas, é a compreensão de que não há repetição do mesmo. O que há é uma tentativa de controle, uma busca pela pausa, pelo momento certo da suspensão que ora está na entonação, própria da poesia, no espasmo fantasma da dor, na linguagem; mais que isso, amor é o espaço entre a prótese e a perna, entre o olhar do filho e do pai, os galopes lidos no poema e retomados pela lembrança.

Assim sendo, para ambos, o amor vincula o lúdico ao poético do fazer artístico; instiga o olhar, que ultrapassa o tempo, que transforma os gestos, fazendo do banal algo espetacular, que coloca em primeiro lugar o contemporâneo - o estar com, o envolver-se com o outro, com o passado. No entanto, o amor como o passado já não se apresenta mais como fantasma, mas como articulador, como uma força geradora que move o presente.

\section{Performances ou modos de esgotar}

No texto de apresentação da versão reeditada dos $X X$ Desenhos, em comemoração aos cem anos de nascimento de Amadeo de Souza-Cardoso, o crítico Carlos Camposa comenta:

Sirva o que digo apenas como anotação e notícia sobre Souza-Cardoso, focadas segundo a minha sensibilidade. Mas o que principalmente nos interessa agora é este ALBUM ousado, perturbador, poético - e sobretudo LITERARIO até à profundeza das suas raízes - porém sempre deslumbrante e magnífico [...] (CAMPOSA, 1987, p. 13, maiúsculas do autor).

$\mathrm{Na}$ mesma edição, Camposa traduz do francês ao português a apresentação de Jérôme Doucet, que ao comentar os desenhos de Amadeo, acaba por sintetizar em vertiginosos traços, certas tendências ex-óticas e anacrônicas da modernidade:

\footnotetext{
Muito há aqui de estranho, de imprevisto, de misterioso, mas também muito de imaginação, de emoção, de poesia e de talento. Lembremo-nos que foi o século XVIII que descobriu os artistas chineses, que a arte japonesa foi amada na centúria de XIX, e que no nosso século XX relouca por tudo que seja persa. Ora Cardoso, na sua arte, está também adiantado, porque em verdade ele é Mexicano, Mohicano, vingança da velha terra americana através desse filho de Portugueses que foram à conquista e descoberta transatlânticas. (CAMPOSA, 1987, p. 20)
}

E avalia a série de desenhos em perspectiva comparatista, remetendo-os aos do ilustrador da Salomé, de Oscar Wilde, e aos conhecidos motivos de Gauguin:

Extremamente modernos, mesmo depois da surpresa do cubismo, duma intensidade de preto e branco que só Aubrey Beardsley raramente atingiu, de um exotismo de Éden que o próprio Gauguin nunca ultrapassou, eles são empolgantes e marcam uma individualidade (CAMPOSA, 1987, p. 20) 
Doucet e Camposa parecem estar de acordo a respeito da poeticidade da obra do pintor português, mas o primeiro a recupera em dicção antropofágica, novamente reconduzindo-a ao estranhamento, ao barbarismo e ao informe:

Que esta poesia seja bárbara, que este talento seja selvagem como floresta virgem de inquietantes embrechados, ou qual melopeia de tribu antropófaga, de tonalidades aterrorizantes, que importa! É poesia e talento, é coragem, para quem ame a novidade e respeite a sinceridade, a franqueza, mesmo quando brutais. (CAMPOSA, 1987 , p. 19)

Cecilia de Torres, por sua vez, enfatiza em seu texto dedicado a Torres-García, o caráter autodidata que se apresenta desde sua infância no Uruguai, onde preferia ficar envolvido com os afazeres na oficina do pai do que ir à escola.

He also enjoyed opening and assembling the boxes of imported goods, such as sewing machines, furniture, and tractors. In spite of Uruguay's obligatory school education, the young lad regularly ran away preferring to study at home by himself. (TORRES, 2009, p. 12)

Outro fator de cunho modernista observado e sublinhado pela crítica é o abandono de um estilo baseado na arte clássica em favor de outro pautado em pinturas dinâmicas inspiradas num estilo urbano, próprio das cidades modernas da década de 1920. Para De Torres, é de Nova Iorque, desta metrópole, de sua arquitetura, da cultura das ruas que advém a força que faz com que o artista uruguaio rompa com o passado.

He was powerfully impacted by its raw energy, its non-stop motion, its imposing architecture, and by its popular culture: advertising art, cartoons, and the movies. He only stayed for two years, but they were determinant because in New York, TorresGarcía was able to break with the past and consolidate new ideas for future developments. His crowded New York paintings capture the multifaceted aspects of city life; they display the American flag, clocks, buildings, trains, brand product names, the frantic traffic, billboards, and crowds. (TORRES, 2009, p. 12)

Além de dar ênfase ao rompimento com o passado, Cecilia de Torres traz à baila, ao citar Mari Carmen Ramírez, uma leitura que ressalta o caráter heterogêneo da poética de Torres-García que, segundo a curadora convidada, está ligado ao cubismo analítico, ao dadaísmo, ao neo-plasticismo, ao surrealismo e a arte primitiva.

Guest curator Mari Carmen Ramírez, the Wortharm Curator of Latin American Art at the Museum of Fine Arts Houston, wrote they are "unclassifiable objects," and stresses that 'the emphasis on the economy of means and the insertion of extra pictorial values merges with several well-known poetics: Cubism's analytical and synthetic deconstruction of representation; Dada's iconoclastic use of recycled materials; Neo-Plasticism's grid-based metaphysical insights; Surrealism's heaping of bizarre intuitions; and Primitive art, understood as an animistic perception of a natural world with no tradition.' (TORRES, 2009, p. 12-13) 
Ao mesmo tempo em que é exposto o caráter heterogêneo e não tradicional da obra de Torres-García como algo próprio do fazer moderno, vislumbramos outro viés da obra do artista uruguaio que é sua escritura, e que o acompanha e o ajuda a ultrapassar o modernismo pela vontade de ir além das formas pré-estabelecidas pelas vanguardas.

\begin{abstract}
In Paris Torres-García was finally able dedicate all his energy to painting and writing. He met key pioneers of the avant-garde like Piet Mondrian, Jean Arp, and Theo Van Doesburg, and exhibited his work in important art galleries. During this period he wrote introspective texts in search of his own artistic personality. About originality, he wrote to himself: "Walk with faith. Because despite the importance of discovery in art, of the new theory, of the invention, something more important makes the work: that which is really ours and unique to us. That which is really unprecedented [l'inédit] or nonexistent before us." (TORRES, 2009, p. 15)
\end{abstract}

$\mathrm{O}$ inédito/l'inédit unprecedented pensado de maneira singular pode ser uma das facetas para se pensar o informe, ou seja, é uma maneira de transitar tanto pela plástica, quanto pela escritura, de poder se apresentar mais interessado no processo artístico, na reflexão, na troca de idéias, do que na obra acabada, na ideia pronta. Tudo isso nos leva a pensar que ao revisitarmos parte do percurso artístico de Torres-García, podemos compreender que o procedimento, a busca do artista, a vontade de deixar-se envolver pelos jogos, pelos gestos de seus filhos, também se desdobra na contemplação das demais bifurcações da arte. Por isso, a obra poética de Torres-García é por si só, constituída por um processo performático criativo que colocou em movimento não somente as formas, mas o artista cujas preocupações eram tanto artísticas, quanto políticas.

Assim, talvez se possa afirmar que em Souza-Cardoso e em Torres-García há uma vontade de ultrapassar o moderno. E pode-se sugerir ainda que, neles, o esgotamento do moderno se dá ora pelo modo performático provocado pelo eterno retorno, ora pela multiplicidade de registros, que, neste ensaio, se distribuem como verbetes, modos de empregar e proliferar teorias e práticas em torno das artes.

\title{
Referências
}

AGAMBEN, Giorgio. O que é o contemporâneo. Trad. Vinícius Nicastro Honesko. Chapecó: Argos, 2009.

ALFARO, Catarina. In. [Catalogo Raisonné 2] Pintura. Lisboa: Fundação Calouste Gulbenkian, Assírio \& Alvin, 2008.

BATAILLE, Georges. A mutilação sacrificial e a orelha cortada de Van Gogh. Trad.: Carlos Valente. Lisboa: Hiena, 1994. 
"Informe". In: Suplemento. Secretaria de Estado de cultura de Minas Gerais. N. 1316. Belo Horizonte, janeiro de 2009. "Informe". In: Suplemento. Secretaria de Estado de cultura de Minas Gerais. N. 1316. Belo Horizonte, janeiro de 2009.

As lágrimas de Eros. Trad.: Aníbal Fernandes. Lisboa: Sistema Solar, 2012.

BERGER, John. Modos de ver: arte e comunicação. São Paulo: Martins Fontes, 1982.

BOIS, Yve-Alain; KRAUSS, Rosalind. L'informe, mode d'emploi. Paris: Éditions du Centre Pompidou, 1996.

CAMPOSA, Carlos. In. SOUZA-CARDOSO, Amadeo de. Vinte desenhos. Lisboa: Só Livros; Trofa, 1987

CARLOS, Isabel. "Sob o signo de Amadeo: um século de arte". In: Cadernos do CAM. Lisboa: Fundação Calouste Gulbenkian, 2013.

FRANÇA, José-Augusto. Amadeo de Souza-Cardoso. Lisboa: Artis, 1960. [Tiragem especial: Coleção de Arte Contemporânea. Escrito originalmente em francês, Paris]

FOSTER, Hal. Prosthetic gods. Cambridge: Massachusetts Institute of Technology, 2004.

HUIZINGA, Johan. Homo ludens. Trad. João Paulo Monteiro. São Paulo: Perspectiva, 2000.

JOAQUÍN Torres-García. Stedelijk Museum Amsterdam. Dec. 1961 - Jan. 1962. Cat. 288.

MASLACH, Adolfo M. "Del esoterismo en el arte de Joaquín Torres-García. In: FLETCHER, Valerie. Crosscurrents of modernism: four Latin American pioneers: Diego Rivera, Joaquín Torres-García, Wifredo Lam, Matta. Valerie Fletcher with essays by Olivier Debroise... [et al.]. English and Spanish. Catalog an exhibition organized by the Hirshhorn Museum and Sculputure Garden June 11 to Sept. 7, 1992.

[Catalogo Raisonné] Fotobiografia. Lisboa: Fundação Calouste Gulbenkian, Assírio \& Alvin, 2007.

SURYA, Michel. "O Coice do Burro". In: BATAILLE, Georges. A Mutilação sacrificial e a orelha cortada de Van Gogh. Trad.: Carlos Valente. Lisboa: Hiena, 1994.

TORRES, Cecilia de. "The essence of the Art". In: LITERAL. Latino America voices. Bilingual magazine. Houston, otoño/fall, 2009.

WILLS, David. Prosthesis. Stanford, CA: Stanford University Press, 1995.

\section{Internet}

<http://www.torresgarcia.org.uy/index_1.html $>$ Acesso em: maio 2013.

[Recebido e aceito para publicação em dezembro de 2013] 


\section{Vanguards and exhaustion: the stresses of modern art in two artists}

Abstract: The proposed article will investigate two modern artists: the Uruguayan Joaquín Torres-García and the Portuguese Amadeo de Souza-Cardoso. The starting point of this reflection is the entry "Form less" by Georges Bataille, published in 1929 in the journal Critical Dictionary Documents (1929-1931). It brings to us the discussion performed by Rosalind Krauss and Yve-Alain Bois on the occasion of the exhibition L' informe. Mode d' employ. This analysis shed light on the "form less" operation as a performative character.

Building on these theoretical texts, we intend to bring up and discuss the possible consequences of some concepts dear to modernity that circulate around the depletion of vanguards and elaborated in the process simultaneously own movements. Besides this widely recognized work of Krauss and Bois, some critical texts about other works of Bataille and also about the theory of modernity are references throughout this essay, to oppose and show the singularities present into two artistic productions.

Keywords: Modernism. Exhaustion. Joaquín Torres-García. Amadeo de Souza-Cardoso. Avant-gardes.

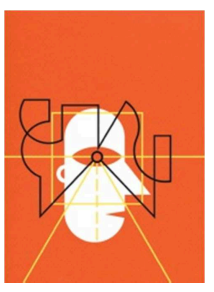

